\title{
TEMPORAL SAMPLING CONDITIONS IN NUMERICAL INTEGRATION OF HYDROLOGICAL SYSTEMS TIME SERIES
}

\author{
Constantin Adrian ŞARPE ${ }^{I}$, Ionel HAIDU ${ }^{2}$
}

DOI: 10.21163/GT_2017.121.09

\begin{abstract}
:
This paper verifies the sampling conditions of discharge and net precipitation series, subjects of integral transforms. The time step influence on the discrete numerical integration of the hydrological system input and output signals was analysed. Our approach is based on the sampling theorem and on the basic properties of the Discrete Cosine Transform (DCT) and of the Fourier integral transform. Arguments from conceptual models of river basin rainfall-runoff are considered to underlie our time series sampling. The application of the integral transform methods like DCT in the Instantaneous Unit Hydrograph (IUH) parameters computation needs to fix the summing limits before designing the numerical procedure.
\end{abstract}

Key-words: Lag time, Instantaneous Unit Hydrograph, Discrete Cosine Transform, Sampling.

\section{INTRODUCTION}

The watershed is the object of this analysis and in the sense of the systems theory it operates on the system input (rainfall) to take it to the output as concentrated flow in river streamflow. The Unit Hydrograph (UH) is the hydrological system response of one unit excess rainfall, evenly distributed in space, as defined by Sherman (1932). The Instantaneous Unit Hydrograph (IUH) is the system output (streamflow) when the time length of input (the effective rainfall burst) collapses to zero (Nash, 1957; Raymond, 2003).

Even if it is a simple theoretical concept, IUH allows elegant mathematical approaches of hydrological issues. The model that we will analyse here is based on formal equivalence of a time invariant linear system IUH, and cumulative time-area diagram in Clark's (1945) UH theory. System output is made explicit in both cases by convolution integrals:

$$
\begin{aligned}
& q(t)=\int_{0}^{t} h(\omega) r(t-\omega) d \omega=\int_{0}^{t} h(t-\omega) r(\omega) d \omega \\
& q(t)=\int_{0}^{t} A(\omega) r(t-\omega) d \omega=\int_{0}^{t} A(t-\omega) r(\omega) d \omega
\end{aligned}
$$

1 Romanian Waters National Administration, Mures Branch, 540057 Targu Mures, Romania, adrian.sarpe@dam.rowater.ro;

2 Université de Lorraine, Laboratoire LOTERR-EA7304, 57045 Metz Cedex 01, France, ionel.haidu@univ-lorraine.fr 
where: $q(t)$ is the streamflow discharge; $r(\omega)$ is the effective rainfall; $h(\omega)$ is the IUH transfer function; $A(\omega)$ is the cumulative time-area diagram and comparing the above relationships we can formally identify the last two parameters:

$$
\boldsymbol{h}(\omega)=A(\omega)
$$

This equation reveals a possible physical meaning of the IUH transfer function, $h(\omega)$, i.e. the areagram of infinitesimal areas of the same runoff time until the control section.

Because of finite time measuring of rainfall intensity and of liquid flows and the discrete value representation of numerical series, the hydrological system input and output are discrete time dependent functions. If $D$ is a finite time interval and the functions values are known at the $n D$ moments, where $n=1,2, \ldots, N$, then the equations (1.1) are:

$$
\begin{aligned}
& q(k D)=D \sum_{n=0}^{k} h(n D)_{r}(k D-n D)=D \sum_{n=0}^{k} h(k D-n D) r(n D) \\
& q(k D)=D \sum_{n=0}^{k} A(n D) r(k D-n D)=D \sum_{n=0}^{k} A(k D-n D)_{r}(n D)
\end{aligned}
$$

here $h(t)$ is the Unit Hydrograph of a $D$ lasting time rain (UHD).

Different methods which sought to fit a watershed IUH have been published in the scientific literature: hydromorphological parameters based, direct linear or nonlinear programming, least squares adjustment, statistical moments, and integral transforms. The main approach in the transformation methods consists in converting the hydrological system representation from temporal to frequency domain.

\section{FOURIER COSINE TRANSFORM OF HYDROLOGICAL SYSTEMS TIME SERIES}

There is a wide variety of problem solving appropriate integral transforms and one of the objectives in the IUH theory is, in terms of systems theory, to derive the transfer function knowing the input and output functions. Recall here that the original function and the image function in a pair of integral transforms are only different representations of the same function in different domains.

The rainfall intensity and streamflow discharge functions in rainfall-runoff process are defined on a closed time interval and are real functions of real variable with non-periodical oscillations.

An integral transform widely used in spectral analysis of real value series, mainly in digital signal processing, but also appropriate to transform hydro-meteorological variables, is Fourier Cosine Transform (FCT), directly derived from Fourier integral transform. In order to estimate the IUH transfer function we need to calculate the system response FCT function $Q(\omega)$ as image of the streamflow discharge $q(t)$ :

$$
Q(\omega)=\int_{0}^{\infty} q(t) \cos (\omega t) d t
$$


and the system impulse FCT function $R(\omega)$ as image of the excess rainfall $r(\omega)$ :

$$
R(\omega)=\int_{0}^{\infty} r(t) \cos (\omega t) d t
$$

Even if the integral form of the FCT in the above-mentioned equations might be useful to derive some general definitions in the IUH theory, it needs to be rewritten to process positive, real value time series, sampled as data of finite duration. This reformulation to discrete time used in effective numerical calculus is known as Discrete Cosine Transform (DCT).

Eight types of DCT were defined (Wang and Hunt, 1985), but only two of them are commonly used in numerical applications. To keep the presentation simple and without affecting the results of our analysis, the integral transforms (2.1) and (2.2) are rewritten in DCT-I type/version (Yip, 2000):

$$
\begin{aligned}
& \boldsymbol{Q}(m)=\sqrt{\frac{2}{N}} \sum_{n=0}^{N}\left(k_{m} k_{m} \cos \left(\frac{m n \pi}{\mathbb{N}}\right) q(n)\right) \\
& \boldsymbol{R}(m)=\sqrt{\frac{2}{N}} \sum_{n=0}^{N}\left(k_{m} k_{n} \cos \left(\frac{m n \pi}{N}\right) r(n)\right)
\end{aligned}
$$

The inverse DCT transform is:

$$
\boldsymbol{h}(m)=\sqrt{\frac{2}{N}} \sum_{n=0}^{N}\left(k_{m} k_{n} \cos \left(\frac{m n \pi}{N}\right) H(n)\right)
$$

where

$$
k_{i}= \begin{cases}1 & \text { for } i \neq 0 \text { or } \mathbb{N} \\ \frac{1}{\sqrt{2}} & \text { for } i=0 \text { or } \mathbb{N}\end{cases}
$$

Here the $N$-vectors $\boldsymbol{H}, \boldsymbol{Q}, \boldsymbol{R}$, are the DCT images of the $N$-vectors $\boldsymbol{h}, \boldsymbol{q}$ and $\boldsymbol{r},(m, n=0,1,2$, ...N).

Knowledge of the optimal value of the summing limit $N$ in the series (2.3), (2.4) and (2.5) is critical in the effective implementation of numeric algorithm. Too large values lead to steep increase of operation number and expanding of computing time, while small values of $N$ have the effect of details neglecting and therefore important errors in rainfall-runoff process modelling. With the goal of a precise calculation of integrals (1.3a), (1.3b) and of integral transforms (2.3) and (2.4), the present work searches to formulate criteria to an optimal time step $D$ inference. 


\section{THE SAMPLING THEOREM}

Optimization is based on Nyquist-Shannon sampling theorem that precisely defines the required number of samples $N$, in order to ensure the exact reconstruction of the initial signal, a time-limited, continuous function.

The Sampling Theorem (Lerman, 2015): If an absolutely integrable function $x(t)$ contains no frequencies higher than $B$, then it is completely determined by its samples at a uniform grid spaced at distances $1 /(2 B)$. The recovery formula is:

$$
x(t)=\sum_{n} x\left(\frac{n}{2 B}\right) \sin c\left(2 B\left(t-\frac{n}{2 B}\right)\right)
$$

where $x(n / 2 B)$ is the sampled signal.

The theorem asserts that sampling should be done at a step time less than or equal to the interval between two significant details of the continuous function $x(t)$, e.g. a local minimum and a local maximum. All other possible features of the function between two successive values at one time step interval $(1 / 2 B)$ will be removed following the sampling.

\section{THE TEMPORAL FEATURES OF RAINFALL-RUNOFF PROCESS}

Essentially, the working method proposed here to estimate the upper summing limit $N$ in direct and inverse DCT (2.3)-(2.5) is perfectly suitable for the analysis of singular events.

The steps are as follows:

1) Verify the sampling theorem and calculate the grid distance in the streamflow discharge time series $q(t)$.

2) Verify the sampling theorem and calculate the grid distance in the effective rainfall time series $r(t)$.

3) Calculate the lag time of the analysed rainfall-runoff process. As it is stated in the lag time definition to be the interval between the moment of storm culmination and the moment of maximum streamflow, this parameter could meet the requirement of the sampling theorem.

4) Choose as time step $D$ the smallest of the values of time intervals calculated at the previous stages of the method. The step number $N$ will be the ratio between the total time and the time step.

Only a physical approach of the processes in the frame of deterministic hydrological models superimposed on the stages of our methodology provides an overall theoretical perspective of the temporal features of rainfall-runoff process. Faced with the acute spatiotemporal unevenness of the rainfall distribution as the driving factor of the process, we will have to consider the problem from both perspectives: the temporal perspective as well as the spatial extension. The lag time is a powerful parameter correlating both time series (rainfall and streamflow) and bringing in a single variable the complex effect of all the others watershed hydromorphological parameters (area, length, slope, and roughness). 


\subsection{The spatial extension approach}

Examining the spatial unevenness of storms distribution, we notice the incongruity of the UH theory versus the storms distribution reality. Note here a couple of basic assumptions on the rainfall excess in the UHD theory: it is uniformly distributed over the watershed at a uniform rate, during a specified period of time (Sherman, 1932).

Then, all evaluations should be limited to surfaces of uniform rainfall excess rate, during the time step period $D$. But the theory is widely applied, constantly neglecting both assumptions, by cumulating the rainfall excess over the time step period $D$, and averaging it on the whole river basin.

The fall of a predefined amount of rain in a time interval $D$ over a certain area is just a matter of hazard in this slightly modified approach and with a certain degree of uncertainty; any storm distribution is possible. In a regionalisation over the Romanian territory (Diaconu and Serban, 1994), the same $161 \mathrm{~mm}$ in 24 hours storm has a return period of 100 years in a $1000 \mathrm{~km}^{2}$ river basin and a return period of 20 years in a $4 \mathrm{~km}^{2}$ watershed.

Coming back to the physical meaning of the transfer function in the IUH theory as cumulative time-area diagram, in (1.1b) $A(\omega)$ is the elementary finite area from where a raindrop reaches the control section after a time interval $\omega$. Or, in terms of the discrete time equation (1.3b), from the finite area $A(n D)$, cumulated excess precipitation in the period of one time step $D$, reaches the control section in the interval of time ranging from $(n-1) D$ to $n D$. Also, overland flow crosses this finite area $A(n D)$, delimited by the upstream and the downstream isochrones, in a time step:

$$
T_{o v}=n D-(n-1) D=D
$$

As we stated above, a more comprehensive integration of the complex effects of watershed parameters variability, including streamflow, is supported by the lag time rather than the overland flow time.

The sampling of cumulative time-area diagram at the time step $D$ is represented by the isochrones of overland flow on the watershed surface. Now it is obvious that there should be a correlation between the time step $D$ and the finite areas of the surfaces delimited by the isochrones ranging in the interval $\left[A_{\min }, A_{\max }\right]$. Spreading over the range of values of the transfer function is the effect of the hydromorphological parameters variability and is also visible as lag time variability. Reciprocally, surfaces of identical areas could be found between isochrones of different time steps.

Partial flow after a rainfall on the smallest surface between two successive isochrones (or from a rain not covering this entire surface, which is then averaged on the whole surface between the two isochronous) reveals the shortest detail which can be identified on a hydrograph. The inverse problem is to estimate the shortest level of temporal details in a hydrograph analysis, based on a fixed minimum value of surface area.

The functional relationship between the watershed area and the lag time $T_{L}=f(F)$ obtained by statistical analysis of more than 50 small Transylvanian watersheds (Sarpe and Voda, 2017) is a raw estimate of the level of temporal details:

$$
\begin{aligned}
& T_{L 1}=44.33+11.27 \mathrm{~F} \\
& T_{L 2}=28.56+6.38 \mathrm{~F}
\end{aligned}
$$


where $T_{L 1}$ and $T_{L 2}$ are lag times in minutes, calculated by two different methods; $F$ is the watershed area in $\mathrm{km}^{2}$. The correlation coefficient was 0.8251 in the first method and 0.7845 in the second.

The results of the applying equations (4.2a) and (4.2b) for several particular values of the river basin area are presented in Table 1. The events with the return probability of 1 in 100 years were considered. The scattering of lag time values in Fig. 1 reveals the effect of the hydromorphological parameters variability. The overland flow time values are in the range of 10 to 75 minutes on surfaces of about $1 \mathrm{~km}^{2}$.

Table 1.

\section{Lag time estimation}

\begin{tabular}{|l|c|c|c|c|c|c|}
\hline $\mathrm{F}\left[\mathrm{km}^{2}\right]$ & 0.1 & 1 & 2 & 4 & 8 & 9 \\
\hline $\mathrm{T}$ Lag1 [min] & 45.5 & 55.6 & 66.9 & 89.5 & 134.6 & 145.9 \\
\hline $\mathrm{T} \mathrm{Lag} 2[\mathrm{~min}]$ & 29.2 & 34.9 & 41.3 & 54.1 & 79.6 & 86.0 \\
\hline
\end{tabular}

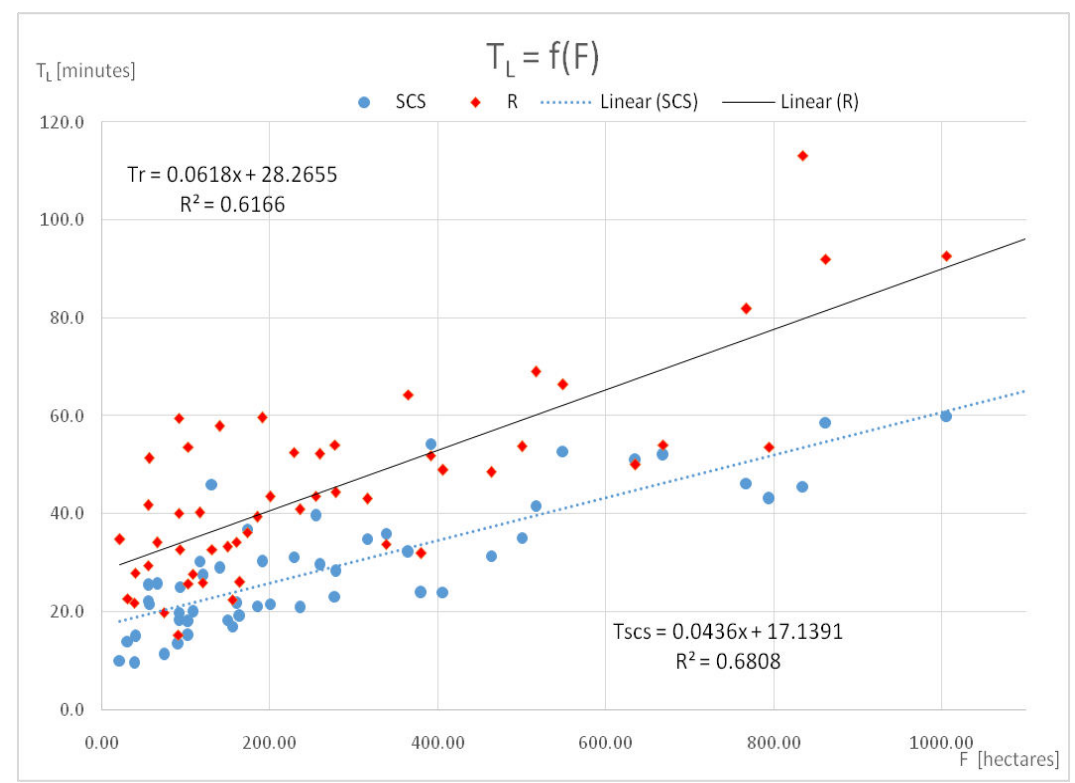

Fig. 1. Lag time versus watershed surface correlation

$T_{L 1}$ was calculated by means of an iterative algorithm (Mejdunarodnoe rukavodstvo pa metodam rasciot asnovih ghidrologhiceskih harakteristic, 1984) known as the rational method. Both components of lag time - overland flow and streamflow - were estimated by the following equations:

$$
T_{o v}=\frac{\sqrt{L_{w}}}{m_{v} \sqrt[4]{i_{w} h^{2}}}
$$


notations are: $\quad L_{v}$ average length of slopes, in meters;

$i_{v}$ average gradient of slopes, in $\mathrm{m} / \mathrm{km}$;

$m_{v}$ a roughness coefficient of slopes;

$h$ average depth of runoff on the slopes, in $\mathrm{mm} / \mathrm{min}$.

$$
T_{s t}=\frac{L_{a}}{m_{a} \sqrt[3]{i_{a} Q^{\frac{3}{4}}}}
$$

where: $\quad L_{a}$ stream length from the spring to the control section, in meters;

$i_{a}$ average gradient of stream, in $\mathrm{m} / \mathrm{km}$ :

$m_{a}$ a roughness coefficient of river bed;

$Q$ maximum streamflow discharge, in $\mathrm{m}^{3} / \mathrm{s}$.

The parameters in equations (4.3) and (4.4) were estimated in the field observations, inferred from thematic maps or from regionalisations.

The concentration time $\left(T_{c o n}\right)$ defined as runoff duration of a raindrop from the watershed's hydraulically most distant point to the control section is:

$$
T_{c o n}=1.2 \times T_{s t}^{1.1}+T_{0 V}
$$

It should be noted that this point is not necessarily the most distant point, but it is the point where the maximum time is required to reach the control section. And the lag time is (Simas, 1996):

$$
T_{L l}=\frac{3}{5} T_{c o n}
$$

Lag times $T_{L 2}$ (in hours) in the second method were calculated directly (National Engineering Handbook, 1997):

$$
T_{L 2}=\frac{L^{0.8}(S+1)^{0.7}}{1900 \sqrt{I_{v}}}
$$

where $L$ is the stream length, in feet;

$I_{v}$ average gradient of slopes, in \%;

$S$ maximum potential retention, in inch.

Due to the ribbon shape of the specific watershed elementary surfaces in (1.1b), the overland flow is the main component of the lag time (4.6) and it is not the best choice to assimilate the elements of cumulative time-area diagram as little independent watersheds. This approach is more suitable to integrate the runoff in Geomorphological Unit Hydrograph (GUH) (Lopez et al., 2005) models.

Then the time step proportionality to the square root of the slope length is more relevant, as in equation (4.3). The smallest possible values are represented in Fig. 2, and they are in the 12 (when the slope gradient is $40 \%$ and the length is 180 meters) to 20 
minute range if the length is 470 meters and slope gradient is $35 \%$, but at rainfall rates greater than $1 \mathrm{~mm} / \mathrm{min}$ this time interval could be even smaller. Keeping the same watershed parameters and applying the (4.7) equation the lag time is 11.4 minutes and 26.3 minutes respectively, consistent with those obtained by the first method.

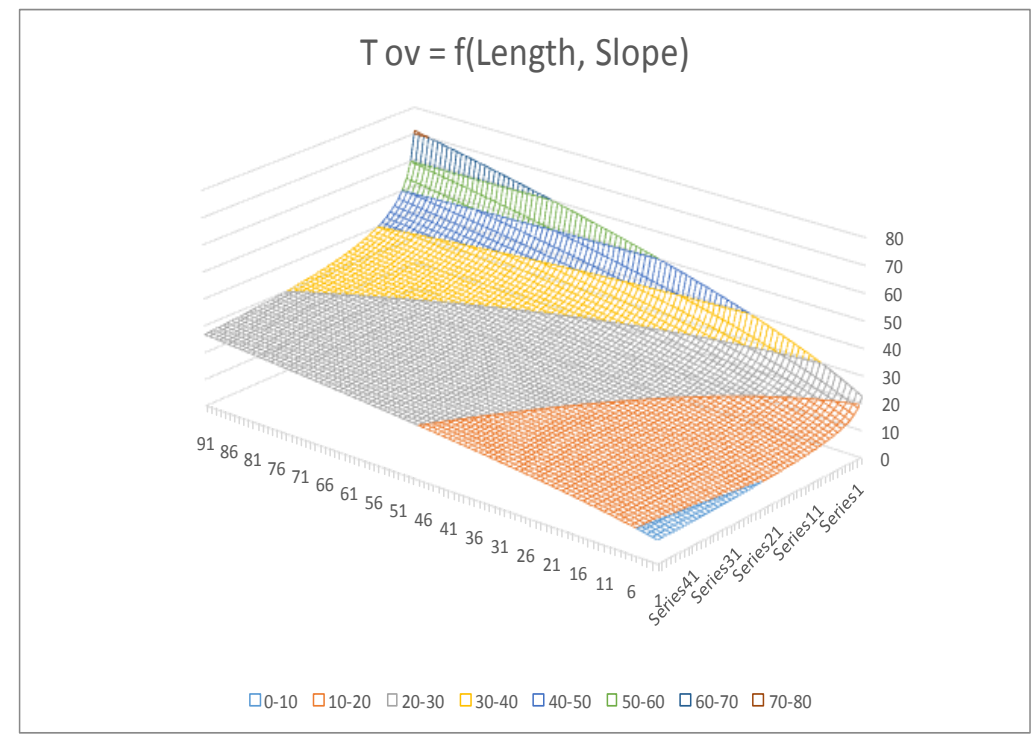

Fig. 2. Overland flow time in correlation with length and gradient of the slopes

Time steps in the range of 10 to 30 minutes are applicable in rainfall excess integration through cumulative time-area diagram in the (1.3) type relation. To maintain the visible small watershed components (greater than $1 \mathrm{~km}^{2}$ ) contribution to integral transforms (2.3), the time step should never exceed values of 30-60 minutes. A 53.5 minutes lag time in the W1420 tributary of Monorastia river located in a low slope region and in a storm smaller than one in 20 years return probability (Györi and Haidu, 2011) is in the range of our recommendations.

\subsection{The temporal approach}

Coming back, we highlight the acute discrepancy between the temporal unevenness of the rainfall distribution and the basic assumption in the UH linear theory that the rainfall excess is of constant rate on each integration step time interval $D$, throughout the entire river basin. As the isohyets of a rainfall have a prevailing perpendicular direction to the runoff isochronous, this will generate a hydrograph similar enough to the measured one, if there is sufficient information to calculate an average rainfall distribution throughout the watershed or if a re-adjusting of the net storm rain parameters is conducted. If the isohyets of the rainfall have a predominant direction parallel to the runoff isochronous, then the net storm rain will be very difficult to adjust in any way so that the UH parameters generate real, measured values of flood peak flow, of the total volume and of the peak moment. 
By verifying the sampling theorem on the rainfall time series (the second stage of our methodology), we could apply a general relationship between the lag time and the rain duration $T_{r}$ (Taylor and Schwarz, 1952):

$$
T_{r}=\frac{2}{11} T_{L}
$$

Depending on the temporal distribution of precipitation intensity, the time duration to maximum is a fraction of $T_{r}$ and a rather good estimation is the half of this interval:

$$
D=T_{r} / 2=T_{L} / 11
$$

In real case sampling of rainfall excess, the step time will be selected according to the shortest feature we want to be preserved from the rainfall time series and this could be the best option in choosing the step time. The question is whether this level of temporal sampling is really absolutely necessary and what errors would the extension of this time interval involve? For instance, in the Neagra river basin, in a 22 meters raster grid, the sampling time was just 1 minute (Domnita et al., 2010).

Maximum effects are expected in the three scenarios presented below. If during the time interval $k D$, cumulated precipitation is $H$, but the rainfall lasted in fact only a $1 / k$ fraction of this interval, the effect on the resulting hydrograph from the convolution integral (1.3) is that of decreasing and delaying the calculated maximum which occurs now with a delay of about $0.5 \times k D$.

Another possibility to distribute the $H$ precipitation cumulated during the $k D$ time interval is the occurrence of two events of $H / 2$ cumulated precipitation and duration $D$, at the beginning and at the end of the $k D$ time interval. According to the IUH characteristics and the size of the $k$ factor, the resulting hydrograph is possible just to widen or even arrive to show two separate peaks, simultaneously with a peak value decrease and a total volume remaining constant as in first scenario. For a numerical illustration of the above scenarios, a synthetic Nash-type HU was applied for the 10 minutes rainfall in the Scroafa river basin at Saschiz gauge station $(\mathrm{n}=13.95$ and $\mathrm{k}=0.477)$. The $100 \mathrm{~km}^{2}$ river basin area in the Transylvanian Plain and Plateau cumulated depths at different time intervals and the return probability of once in 100 years are presented in Table 2 (Diaconu and Serban, 1994).

Table 2

\section{Different duration area cumulated storms in a $100 \mathrm{~km}^{2}$ river basin area for a return probability of once in $\mathbf{1 0 0}$ years}

\begin{tabular}{|l|c|c|c|c|c|c|}
\hline Duration & $10^{\prime}$ & $30^{\prime}$ & $1 \mathrm{~h}$ & $3 \mathrm{~h}$ & $6 \mathrm{~h}$ & $24 \mathrm{~h}$ \\
\hline Depth [mm] & 60.0 & 93.1 & 109.6 & 132.4 & 151.0 & 206.9 \\
\hline
\end{tabular}

The $188.9 \mathrm{~m}^{3} / \mathrm{s}$ discharge peak occurs after 370 minutes from the start of a 10-minute and $60 \mathrm{~mm}$ net storm rain. The same quantity net storm rain, but cumulated in 60 minutes from a constant rate rainfall generates a peak flow of $186.2 \mathrm{~m}^{3} / \mathrm{s}$ after 390 minutes from the start of the rainfall. Two bursts of 10-minute rainfalls with the same 60-minute cumulated net storm rain, evenly distributed between the two events, at a 40-minute interval, generates a $183.4 \mathrm{~m}^{3} / \mathrm{s}$ peak flow at the same time interval as in the case of a uniformly distributed rainfall (Fig. 3). 


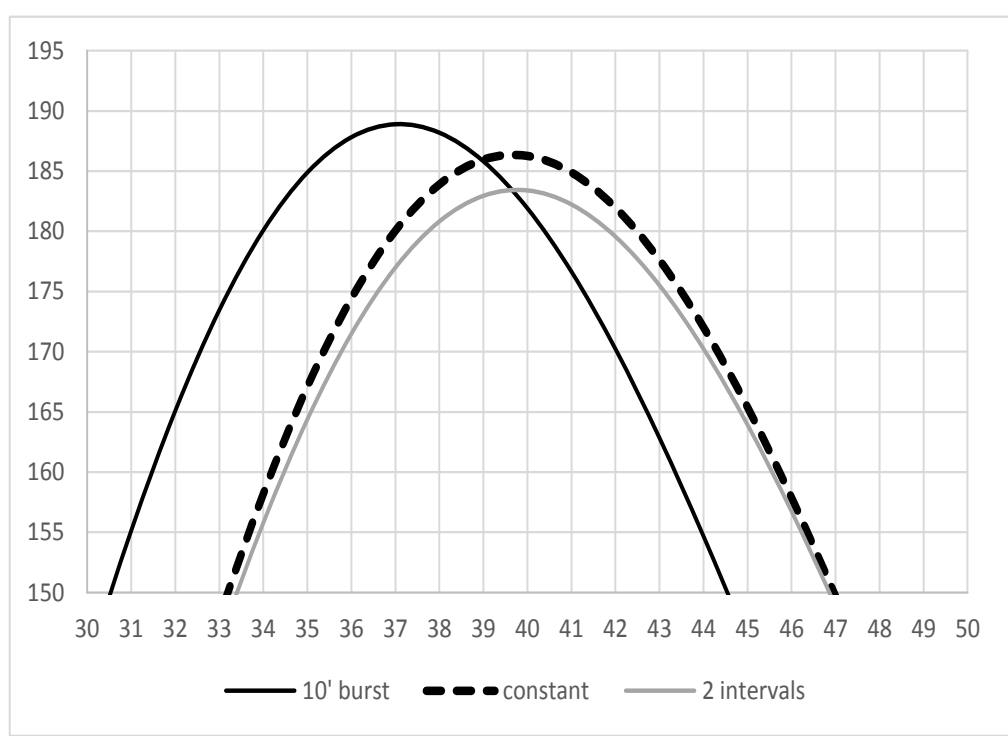

Fig. 3. Peak flow hydrographs of different temporal storm distributions $(60 \mathrm{~mm})$

A constant rate $132.3 \mathrm{~mm}$ net storm rain in a 3-hour rainfall generates a $369.2 \mathrm{~m}^{3} / \mathrm{s}$ flow peak after 460 minutes from the start of the storm. Only a $311.2 \mathrm{~m}^{3} / \mathrm{s}$ flow peak after 490 minutes from the start of the storm is generated by two rainfall bursts of cumulated net storm rain of $66.15 \mathrm{~mm}$ in 30 minutes separated by a 160 -minute pause. The shape of the hydrograph starts to change while the time interval with flow rates higher than half of the peak flow increases from 280 minutes to 330 minutes. The second peak starts to be clearly seen in hydrograph only if the two rainfall bursts are at least 230 minutes apart. If the entire depth of net storm rain of $132.3 \mathrm{~mm}$ is cumulated in the first 30 minutes of the storm, the $415.5 \mathrm{~m}^{3} / \mathrm{s}$ peak flow of the hydrograph will be after 380 minutes from the beginning of the rainfall (Fig. 4). All the results of the above numerical tests of time distribution rainfall scenarios are presented in Table 3.

Effects of different temporal storm distributions

Table 3

\begin{tabular}{|l|c|c|c|c|c|c|c|}
\hline Depth & \multicolumn{3}{|c|}{$60 \mathrm{~mm}$} & \multicolumn{4}{c|}{$132.4 \mathrm{~mm}$} \\
\hline $\begin{array}{l}\text { Time } \\
\text { interval }\end{array}$ & \multicolumn{3}{|c|}{$1 \mathrm{~h}$} & \multicolumn{3}{c|}{$3 \mathrm{~h}$} \\
\hline Distribution & constant & first 10' & $\begin{array}{c}30 \mathrm{~mm} \\
+ \\
30 \mathrm{~mm}\end{array}$ & constant & $\begin{array}{c}\text { first } \\
30^{\prime}\end{array}$ & $\begin{array}{c}66.2 \mathrm{~mm}+ \\
66.2 \mathrm{~mm} \\
\text { in 30' at } \\
2 \mathrm{~h}\end{array}$ & $\begin{array}{c}66.2 \mathrm{~mm}+ \\
66.2 \mathrm{~mm} \text { in } \\
30^{\prime} \text { at 3h }\end{array}$ \\
\hline $\begin{array}{l}\text { Q max } \\
{[\mathrm{m} 3 / \mathrm{s}]}\end{array}$ & 186.2 & 188.9 & 183.4 & 369.2 & 415.5 & 311.2 & $\begin{array}{c}211.4 \text { and } \\
250.8\end{array}$ \\
\hline $\begin{array}{l}\text { T rising } \\
{[\text { minutes] }}\end{array}$ & 390 & 370 & 390 & 460 & 380 & 490 & 380 and 570 \\
\hline $\begin{array}{l}\text { Width at } \\
\text { Qmax /2 }\end{array}$ & 250 & 250 & 260 & 280 & & 330 & 450 \\
\hline
\end{tabular}




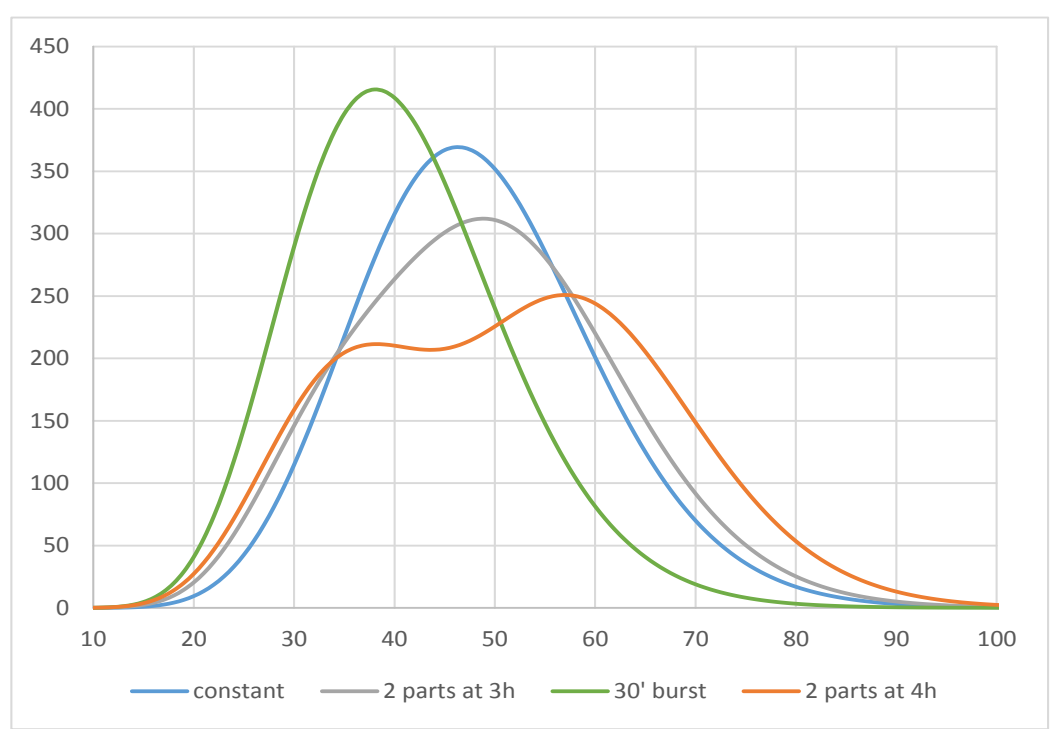

Fig. 4. Hydrographs of different temporal storm distributions (132.3 mm)

The conclusion of this numerical test of time distribution rainfall scenarios is that we can multiply the rainfall cumulating time by a $k$ factor, but only within some limitations imposed by the ratio between the step time and the lag time.

The synthetic UH in the numerical test has a 400-minute lag time and a step time of around $15 \%$ of $T_{L}$ does not lead to significant hydrograph changes, but at $45 \% T_{L}$ ratio differences become hard to neglect. The MIKE 11 software reference manual (DHI, 2009) validates these conclusions and it recommends the use of a time step in the range of 0.22 $0.27 T_{L}$ in the UHM method of numerical integration of SCS hydrographs.

In the temporal approach of applying the Nyquist-Shannon theorem to the hydrograph $q(t)$, the sampling time must be only the peak time $T_{\text {peak }}$, which can be approximated by the equation:

$$
T_{\text {peak }}=T_{L}+\frac{1}{2} T_{r}=\frac{12}{11} T_{L}
$$

i.e. as the sum of lag time and half of the rain duration.

In particular conditions, multiple peaks hydrograph $q(t)$ could be generated by specific structures of the cumulative time-area diagrams or by multipeak net storm rainfall rate distributions. Then the step time should be the minimum one between the first local peak time and the rest of the "peak-to-peak" time intervals.

\section{CONCLUSIONS}

The theoretical estimate of the time intervals that define the step time optimal value for the calculation of the UH transfer functions by methods of integral transform led to the following values: 


$$
\begin{aligned}
& D_{q}=T_{\text {peak }}=\frac{12}{11} T_{\text {lag }} \\
& D_{r} \text { between } \frac{1}{11} \text { and } \frac{1}{6} \text { of } T_{\text {lag }} \\
& D_{\text {lag }}=T_{\text {lag }}
\end{aligned}
$$

where $D_{q}$ is the step time resulting from the hydrograph analysis, $D_{r}$ is the grid time resulting from the rainfall distribution analysis, $D_{\text {lag }}$ is the time interval as the result of the rainfall-runoff process cross analysis. Finally, time step $D$ is the smallest of the values of time intervals calculated before:

$$
D=\operatorname{Min}\left\{D_{q}, D_{r}, D_{l a g}\right\}
$$

Within the applicability limits of the variability conditions of rainfall-runoff timing relationships (4.5), (4.6), (4.8), and (4.11), which define the temporal development of the rainfall-runoff process, the minimum in (5.4) is $D_{r}$, value imposed by the rainfall interval, relaxed after the numerical test mentioned in $T_{\text {lag }} / 6$.

Integral transforms (2.3) time step should never exceed 30-60 minutes, depending on the watershed parameters, if we want to maintain possible distinct visualisation of small watershed components (larger than $1 \mathrm{~km}^{2}$ ) contribution to the hydrograph (Table 1).

Our results are only the framework for an analysis of each event which should be assessed following the criteria proposed above, in the beginning of chapter 4, after a clear representation and identification of all significant features of the river basin, hydrograph and hyetogram.

Checking the sampling conditions of Nyquist-Shannon theorem is not only important for numerical computations of integral transforms, but also for the entire set of hydrological activities, from scheduling the time interval measurements of automatic hydrometric station to ensuring numerical efficiency of rainfall-runoff process representation in the hydrometeorological data base design.

\section{R E F E R E N C E S}

Clark, C.D. (1945) Storage and the Unit Hydrograph. Transactions: American Society of Civil Engineers, 110, 1419-1488.

DHI Water \& Environment, (2009) Mike 11, A Modelling system for rivers and channel, Reference Manual.. MIKE by DHI Horsholm, Denmark, Danish Hydraulic Institute.

Diaconu, C. \& Serban, P. (1994) Sinteze si regionalizari hidrologice. Bucharest, Tehnica Publishing.

Domniţa, M., Crăciun, A. I., Haidu, I. \& Magyari, S. Z. (2010) Geographical Information System module for deriving the flash flood hydrograph in mountainous areas, In: Grigoriu, M., Mladenov, V., Bulucea, C. A., Martin, O., Mastorakis, N. (eds.) Proceedings of the 4th European Computing Conference, Bucharest, World Scientific and Engineering Academy and Society (WSEAS), 260-265.

Gyori, M. M. \& Haidu, I. (2011) Unit Hydrograph Generation for Ungauged Subwatersheds. Case Study: The Monoroştia River, Arad County, Romania. Geographia Technica, 6 (2), 23-29. 
Lerman, G. (2015) The Shannon Sampling Theorem and Its Implications. [Lecture] Notes for Math 5467 Introduction To The Mathematics Of Image And Data Analysis, University of Minnesota, Minneapolis.

Lopez, J. J., Gimena F. N., Goni M. \& Agirre U. (2005) Analysis of a unit hydrograph model based on watershed geomorphology represented as a cascade of reservoirs. Agricultural Water Management, 77 (1-3), 128-143.

Nash, J. E. (1957) The form of the instantaneous unit hydrograph. IAHS General Assembly of Toronto, 3 (45) 114-121.

Raymond, I. J. \& Coon, G. C. (2003) True Form of Instantaneous Unit Hydrograph of Linear Reservoirs. Journal of Irrigation and Drainage Engineering, 129 (1), 11-17.

Sarpe, C. A. \& Voda, I. (2017) Small Watershed Hydrological Models - Lag Time Comparation. In: Horvath, C., Croitoru, A. E., Guettler, I., Man, T. C, Bartok, B. (eds.) 3rd PannEx workshop on the climate system of the Pannonian basin, Cluj-Napoca.

Sherman, L. K. (1932) Stream-flow from rainfall by the unit-graph method. Engineering NewsRecord, 108, 501-505.

Simas, M. (1996) Lag time characteristics in small watersheds in the United States. Dissertation thesis, Faculty of The School of Renewable Natural Resources, The University of Arizona, Tucson.

Taylor, A. B. \& Schwarz H. E. (1952) Unit Hydrograph, lag and peak flow related to basin characteristics. Transactions, American Geophysical Union, 33 (2), 235-246.

USDA Natural Resources Conservation Service (1997), National Engineering Handbook. Part 630 Washington D. C, U.S. Dept. of Agriculture.

Wang, Z. \& Hunt, B. (1985) The discrete W-transform. Applied Mathematics and Computation, 16, $19-48$.

Yip, P. (2000) Sine and Cosine Transforms. In: Poularikas, A. D (ed.) The Transforms and Applications Handbook. Second Edition, Boca Raton, CRC Press LLC.

*** (1984) Mejdunarodnoe rukavodstvo pa metodam rasciot asnovih ghidrologhiceskih harakteristic, Leningrad. 